\title{
Vigilância e privacidade, no contexto do big data e dados pessoais: análise da produção da Ciência da Informação no Brasil
}

\author{
Yuri Monnerat Lott ${ }^{I}$ \\ Regina de Barros Cianconi ${ }^{I I}$
}

${ }^{I}$ Fundação Getúlio Vargas, Rio de Janeiro, RJ, Brasil; Mestre em Ciência da Informação pela Universidade Federal Fluminense (UFF). Membro do grupo de pesquisa Gestão e Uso da Informação e do Conhecimento (UFF).

\footnotetext{
${ }^{I I}$ Universidade Federal Fluminense, Rio de Janeiro, RJ, Brasil; Doutora em Ciência da Informação pela Universidade Federal do Rio de Janeiro/IBICT. Professor associado da Universidade Federal Fluminense.
}

http://dx.doi.org/10.1590/1981-5344/3313

Apresentam-se resultados de pesquisa exploratória e analítica realizada na literatura nacional e estrangeira, reunindo aspectos socioculturais, político-legais, tecnológicos e metodológicos, para entendimento do atual regime de vigilância de massa com aplicação das tecnologias sobre dados pessoais. Buscou-se identificar trabalhos recentes sobre os temas vigilância $e$ privacidade, relacionados aos termos big data e dados pessoais, nas pesquisas acadêmicas da Ciência da Informação, no Brasil. Foram consultados os anais do Encontro Nacional de Pesquisa em Ciência da Informação - ENANCIB, nos últimos 10 anos. Os resultados demonstraram que 7 pesquisas abordaram o tema vigilância com o mesmo enfoque desta pesquisa, e os GTs que mais contribuíram foram os GT 3 e 5, com duas publicações cada. Sobre privacidade, 6 publicações abordaram o tema com o mesmo enfoque desta pesquisa, sendo o GT 5, o que mais contribuiu, com três publicações. Conclui-se que ainda são incipientes as pesquisas da Ciência da Informação nessas temáticas.

Palavras-chave: Vigilância. Privacidade. Big Data. Dados Pessoais. ENANCIB. 


\section{Surveillance and privacy, in the context of big data and personal data: analysis of the production of Information Science in Brazil}

It presents exploratory and analytical research carried out in the national and foreign literature, bringing together sociocultural, political-legal, technological and methodological aspects, to understand the current regime of mass surveillance with the application of technologies on personal data. We sought to identify recent works on the topics of vigilance and privacy, related to the terms big data and personal data, in the academic researches of Information Science in Brazil. It was initially conducted a survey in the literature, to clarify, contextualize and relate the highlighted themes. The annals of the National Meeting on Information Science Research - ENANCIB were consulted in the last 10 years. The results showed that 7 surveys approached the subject of vigilance with the same focus of this research, and the Working Groups that contributed the most were WGs 3 and 5, with two publications each. Regarding privacy, 6 publications were identified for addressing the topic with the same approach used in this research, with WG 5 contributing the most with three publications. It was concluded that research on Information Science in Brazil is still incipient in these themes.

Keywords: Surveillance. Privacy. Big Data. Personal Data. ENANCIB.

Recebido em 17.10.2017 Aceito em 20.09.2018

\section{Introdução}

A transparência dos termos de uso e políticas de privacidade dos serviços digitais, que envolvem material de natureza pessoal e sensível, está sendo questionada e muitos debates públicos vêm sendo travados no sentido de exigir leis que garantam efetivamente a privacidade como um dos maiores direitos do indivíduo. Neste cenário, grupos em posições opostas têm se formado - exigindo garantias para a segurança dos dados e a privacidade, ou apoiando políticas de compartilhamento de informações pessoais em prol da segurança pública. 
Tanto no âmbito governamental quanto no setor privado, percebese que as organizações estão cada vez mais informatizadas e muitas desenvolveram seus próprios sistemas de gestão da informação, pois o atendimento e a prestação de serviços ao usuário, cliente ou cidadão, demandam a utilização de informações pessoais em meio digital para maior agilidade e acurácia na sua recuperação e análise.

Por outro lado, o aproveitamento indevido de informações pessoais vem se tornando cada vez mais frequente, o que traz à tona discussões sobre os critérios de segurança dos bancos de dados e a transparência das políticas de privacidade que devem assegurar aos usuários a propriedade sobre seus dados.

Outro ponto a ser destacado é a possibilidade (e a capacidade cada vez maior) de captação de dados a partir dos meios digitais. Para que um fato, evento ou instância da realidade possa ser computado, é necessário que este objeto seja convertido em um formato passível de ser reconhecido e processado pelos computadores. Nas palavras de MayerSchonberger e Cukier (2013), tudo deve ser dataficado, e esse processo de conversão difere substancialmente da simples digitalização uma vez que os diversos parâmetros do objeto devem estar estratificados e disponíveis para operações computacionais e análises algorítmicas.

Torna-se, portanto, relevante, não apenas ressaltar a configuração atual dos regimes de poder estabelecidos pela captação, processamento e análise de conjuntos massivos de informação, pelos sistemas de big data para fins comerciais, mas também contribuir para o entendimento de um panorama mais amplo sobre as tecnologias de gestão da informação, sobretudo no âmbito pessoal, que possibilitaram e resultaram na crise atual, onde se destacam a falta de privacidade e liberdade.

Considerando o atual dilema entre a necessidade de segurança e a consequente perda de privacidade com o compartilhamento de dados pessoais, no momento em que grande parte da população mundial marcha sobre a esteira globalizante e se torna cada vez mais dependente das novas tecnologias de informação e comunicação (NTIC), foi realizada pesquisa com o intuito de responder à seguinte questão: Qual vem sendo a atenção dedicada às temáticas da vigilância e privacidade - relacionadas a big data e dados pessoais -, nas pesquisas científicas recentes da Ciência da Informação, no Brasil?

Para tanto, foi realizado inicialmente um levantamento na literatura, de carácter exploratório e analítico, com consulta a livros, periódicos (jornais e revistas), teses, dissertações e artigos científicos no âmbito da Ciência da Informação e outros campos, como a Sociologia e a Tecnologia da Informação, na observância de estudos que se mostraram pertinentes para o esclarecimento dos problemas existentes nas relações entre poder e sociedade, as instituições e os indivíduos, e em questões relacionadas à dicotomia entre liberdade e segurança, como vigilância, privacidade, big data e dados pessoais.

Para identificar como a Ciência da Informação, no Brasil, vem incluindo tais temáticas em suas pesquisas, foram consultados os Anais do 
Encontro Nacional de Pesquisa em Ciência da Informação (ENANCIB), dos últimos 10 anos.

\section{Vigilância: das instituições disciplinares à sociedade de controle}

Wood et al. (2006, p. 4, tradução nossa), definem vigilância como "a observação de informações pessoais, de forma proposital, rotineira e sistemática para fins de controle, direitos e legitimidade, gestão, influência ou proteção". Andrejevic e Gates (2014) acrescentam o fato da vigilância de massa se utilizar de grandes bases de dados para identificar e reconhecer de padrões de comportamento, de forma automática e massiva.

A vigilância é um termo cuja definição pode não ter se alterado ao longo do tempo, mas, na prática, suas formas e métodos se adaptaram conforme as novas possibilidades tecnológicas, sobretudo, àquelas voltadas para a observação e cerceamento de indivíduos.

As atividades nos campos da disciplina, controle e segurança também migraram do campo analógico para o digital. Segundo Foucault (1987), as instituições disciplinares - a exemplo dos hospitais, fábricas e escolas - dependiam de uma estrutura física para a manutenção da ordem sobre um determinado grupo de indivíduos. Naquele tempo, os métodos de vigilância eram baseados em dispositivos de ordenação e discriminação dos corpos - corredores, baias, catracas, formulários de registro, cartões ponto, etc. Uma das maiores propostas para a execução desse modelo operacional foi o projeto do complexo penitenciário idealizado por Jeremy Bentham, na Inglaterra do final do séc. XIX: o Panopticon.

No Panopticon, tudo seria feito para facilitar a observação dos corpos e garantir a identificação de qualquer comportamento adverso a um padrão de normalidade estabelecido pela autoridade disciplinar. Segundo Foucault (1987), este era mais que um projeto arquitetônico: um dispositivo que visava a disciplina e o controle através de seus aspectos funcionais.

[...] na periferia uma construção em anel; no centro, uma torre; esta é vazada de largas janelas que se abrem sobre a face interior do anel; a construção periférica é dividida em celas, cada uma atravessando toda a espessura da construção; elas têm duas janelas, uma para o interior, correspondendo às janelas da torre; outra, que dá para o exterior, permite que a luz atravesse a cela de lado a lado. Basta então colocar um vigia na torre central, e em cada cela trancar um louco, um doente, um condenado, um operário ou um escolar. Pelo efeito da contraluz, pode-se perceber da torre, recortando-se exatamente sobre a claridade, as pequenas silhuetas cativas nas celas da periferia. Tantas jaulas, tantos pequenos teatros, em que cada ator está sozinho, perfeitamente individualizado e constantemente visível (FOUCAULT, 1987, p. 165166). 
Portanto, o efeito mais notável do Panopticon, sobre os indivíduos encarcerados, era o de manter a disciplina por antecipação, criando um estado de tensão e sensação de vigilância constantes. Segundo Foucault (1987, p. 167), o projeto de Bentham teria declarado o princípio do Poder visível e inverificável, e que o Panopticon seria a máquina capaz de dissociar o par ver-ser-visto, na qual a torre central criava uma entidade censora despersonalizada e atemporal - o estado de vigilância era constante, independente de quem estivesse no posto de observação e mantida, até mesmo, quando efetivamente não houvesse qualquer agente no posto.

Em estudo posterior, Deleuze (1992) deu continuidade à crítica aos dispositivos adotados pelos meios de produção, em geral, baseados no controle dos recursos humanos. Segundo o autor, diferente das instituições disciplinares, as formas de controle surgidas ao final do século XX não estavam restritas ao confinamento e visibilidade direta dos corpos. Elas aprimoraram o processo de utilização da informação como meio representante dos indivíduos e, através dela, puderam tornar o regime de vigilância ainda mais pervasivo e eficiente.

Deleuze cita a linguagem numérica, não necessariamente binária, e a utilização de recursos digitais (diferentes dos analógicos) muito superiores na sua capacidade de reconhecer padrões numéricos, identificar estados e situações, e estabelecer a distinção entre os indivíduos dentro da massa.

Um dos aspectos enfatizados pelo autor é a superação do modelo de confinamento por instrumentos de controle normativos que incentivam o indivíduo a seguir um padrão de comportamento esperado e desejado para realizar seus objetivos. As cifras são mencionadas como um recurso de identificação que permitem o acesso à informação ou a sua restrição e os tipos de máquinas (ou recursos tecnológicos) são adotados como referência para a observação da capacidade de cada regime (disciplinar ou de controle) em manter a ordem ou a normalidade desejada sobre as populações: "as máquinas simples ou dinâmicas para as sociedades de soberania, as máquinas energéticas para as de disciplina, as cibernéticas e os computadores para as sociedades de controle" (DELEUZE, 1992, p. 216).

Com o advento de novos recursos para a gestão da informação, o monitoramento dos indivíduos, portanto, deixou de ocorrer de forma direta e passou a ser feito de forma mediada, através dos dados que os representam. Deste modo, segundo alguns autores, a vigilância ampliou seu spectrum (HOOKWAY, 2000), tornou-se distribuída (BRUNO, 2013) ou líquida (BAUMAN; LYON, 2013) e ampliou seu poder de ubiquidade a escalas continentais, expandindo sua capacidade de visualização e rastreamento dos indivíduos ao nível das populações.

Braman (2006) ressalta o conceito de panspectron proposto por Hookway (2000), que no início dos anos 2000 era considerado mera teoria ou especulação, mas que nos dias atuais tem evidências incontestáveis da sua existência. Basta considerar a toda tecnologia disponível para o 
monitoramento, localização e identificação de indivíduos, desde os circuitos fechados de TV (CFTV) aos chips de identificação por radiofrequência (RFID). Outros meios como os sistemas digitais de gestão da informação, as ferramentas pessoais de acesso à Internet e o sistema de transações bancárias, são exemplos de a observação não se faz mais de forma pontual a cada indivíduo e diretamente aos corpos. Atualmente, as ferramentas intermediárias (ou mediações) são partes essenciais do modelo de vigilância, para ampliar a capacidade de atuação do centro de poder na identificação dos padrões que destoem da normalidade. Segundo Braman (2006), outra característica do panspectron difere do antigo modelo proposto por Bentham: as informações são coletadas por atacado, de forma abrangente, sem distinção ou limite de tempo. No padrão atual, o indivíduo é identificado somente em caso de necessidade - quando algum padrão notado em seu conjunto de dados acuse alguma ameaça. Então, as informações pessoais desse indivíduo são investigadas com mais atenção, além dos algoritmos, por agentes humanos.

Fernanda Bruno (2013), por sua vez, propõe o conceito de vigilância distribuída para caracterizar o atual cenário em sua capacidade de captação de informações pessoais:

a) seu carácter ubíquo, e descentralizado;

b) a diversidade tecnológica, de dispositivos e de práticas de captação de dados;

c) indiscernibilidade inicial sobre o foco da vigilância;

d) função potencial ou utilização secundária de dispositivos que foram desenvolvidos para outros fins que não a vigilância;

e) função operacional e de análise com a participação de agentes humanos e não-humanos;

f) utilização das redes de entretenimento, notícias e compartilhamento (redes sociais), além das redes especializadas em segurança;

g) participação e colaboração do meio social, de forma independente e não estruturada, por parte dos indivíduos conectados à rede.

Dentre as ferramentas utilizadas estão os sistemas de geolocalização, sistemas de controle de trânsito (particulares ou públicos para o controle de pedestres ou veículos), mecanismos de autenticação (senhas, biometrias, reconhecimento de movimento, etc.), cartões magnéticos, sistemas online, mecanismos de busca, webcams pessoais, entre outros.

A partir desses pontos tecnológicos, Bauman e Lyon (2013), acrescentam alguns aspectos sociais à discussão para o entendimento do atual cenário caracterizado pelo uso intenso de dados pessoais, facilitado pelo compartilhamento voluntário, em grande parte, como forma de 
exposição e recebimento de atenção nas redes sociais. Os autores consideram que um novo campo social se configurou a partir da Internet e das ferramentas de empoderamento do usuário e que o conceito de Rede, em substituição à sociedade, seria o mais adequado para representar a atual relação entre grupos e indivíduos. O cenário desta organização social em rede se caracteriza pela obsolescência programada, pelas respostas rápidas e superficiais, e pelo acesso a todo tipo de conteúdo com o mínimo de esforço. Nesse contexto, os laços de relacionamento entre as pessoas seriam frágeis e tão fáceis de serem estabelecidos quanto desfeitos.

O fenômeno de servidão voluntária - no compartilhamento, abertura e permissão de uso de informações pessoais - também se explica por outros aspectos como (1) a cultura do consumo onde a imagem do estar tornou-se melhor que a essência do ser; (2) a indústria do entretenimento que lucra com a exploração do realismo da vida ordinária e (3) a situação de tensão constante no meio urbano, em função do risco eminente da violência, agravada pela possibilidade de ataques terroristas (BAUMAN, 2001).

\section{Big data e a captura massiva de dados pessoais}

Com a expansão da Internet e com o processo de informatização dos sistemas de gestão, não só a população residente nos grandes centros econômicos, mas também, aqueles que habitam as regiões periféricas e menos desenvolvidas, inevitavelmente, tornaram-se dependentes das tecnologias digitais para ter acesso a serviços e para possibilitar suas ações de trabalho e entretenimento. Neste sentido, o uso de circuitos fechados de câmera, cartões magnéticos e smartphones, além das publicações nas redes sociais, registram os passos e guardam as informações de seus usuários com a precisão de horas, minutos e segundos. Cada click ou toque em uma tela interativa, é suficiente para criar um conjunto de dados que pode conter muitas informações determinantes sobre o indivíduo. Esta questão se torna bastante evidente nos ambientes das redes sociais digitais onde o indivíduo é capaz de compartilhar seus dados pessoais ou transferir, para o domínio público, até mesmo, os bastidores da sua vida mais íntima. O usuário permite (e colabora) com a invasão da sua privacidade para obter audiência ou, em outros casos, permite o uso de suas informações para a sustentação de sistemas de controle, negociando a troca da sua liberdade por uma falsa sensação de segurança (PANOPTYKON FUNDATION, 2015).

Considerando principalmente o processo de informatização para a automação de sistemas no campo governamental e privado, percebe-se um crescimento substancial na geração de dados digitais a partir da década de 2000. Alguns fatores como a popularização dos computadores pessoais e a ampliação da área de cobertura dos serviços de acesso à Internet podem ser citados como causa para o surgimento da web social ou Web 2.0. 
De acordo com a explanação de Tim O'Reilly (2005), a Web 2.0 é um conceito que define o funcionamento da Internet a partir do "estouro da bolha" no ano 2000, quando passou a contar com a colaboração efetiva dos usuários na publicação, revisão e classificação de conteúdo. Nesta segunda fase, a Web passou a ser de fato colaborativa, dando mais poder de publicação para os usuários e permitindo maior interação dos usuários entre si (o que significa o embrião das redes sociais como Twitter, Instagram, YouTube e Facebook, entre tantas outras).

Além dos serviços disponíveis nos sites, surgiram os blogs, as wikis, as tags (etiquetas) e também diversos aplicativos (como o pioneiro Napster, por exemplo) que permitiram a organização de múltiplas redes de compartilhamento de arquivos (O'REILLY, 2005; GOVERNOR; NICKULL; HINCHCLIFFE, 2009). Deste modo, a tecnologia estava não apenas conectando um usuário da Rede a um servidor de conteúdo, mas também a outros usuários, em uma relação de pessoa-para-pessoa (P2P). A noção de como a Web funciona através deste novo padrão colaborativo é de grande importância para entender como a tecnologia e a infraestrutura da Rede - hoje com o amplo acesso sem fio (Wi-Fi) - serviu como ferramenta de organização, mudando radicalmente a forma como as pessoas trabalham e gerenciam suas informações.

Neste sentido, as pessoas estão, cada vez mais, por um lado, adotando novas ferramentas para ampliar suas capacidades de controlar suas próprias informações e, por outro, utilizando dispositivos tecnológicos que captam suas ações e as transformam diretamente em dados (processo de datificação). Com a maior participação popular no ambiente $w e b$, é razoável esperar que a quantidade de dados gerada excedesse a capacidade de infraestrutura instalada para a operação desses dados.

Com as facilidades tecnológicas existentes no atual cenário social e profissional, e nos campos da gestão e da pesquisa, a capacidade de captação de dados foi elevada a instâncias surpreendentes, chegando aos conjuntos de dados massivos. Em 1997, na NASA, o termo big data surgiu para definir, embora de forma não objetiva, a condição de uma base de dados que, pelo volume, velocidade e variedade de dados, excede as capacidades técnicas e de infraestrutura para seu armazenamento, processamento e visualização (DUMBILL, 2012). Ao contrário dos tempos onde o registro das informações era feito basicamente em meio físico, hoje, a vasta presença de dispositivos óticos, leitores magnéticos e sensores dos mais diversos tipos, permite a conversão de objetos, fatos e eventos, do real para o digital, praticamente no momento em que eles ocorrem.

Boyd e Crawford, definem big data como:

um fenômeno cultural, tecnológico e acadêmico baseado na interação de três fatores: (1) Tecnologia: maximização da precisão dos algoritmos e do poder de computação para reunir, analisar, relacionar e comparar grandes conjuntos de dados; (2) Análise: processamento de grandes conjuntos de dados para identificar 
padrões para atender às necessidades de ordem econômica, social, técnica e legal; e (3) Mitologia: a ampla crença de que grandes conjuntos de dados possibilitam uma forma mais avançada de inteligência e conhecimento que podem gerar insights até então impossíveis de se alcançar, de forma objetiva e confiável (BOYD; CRAWFORD, 2012, p. 2, tradução nossa).

A grande questão que move as empresas e os governos para o big data é a (nova) possibilidade de encontrar relações entre pontos distantes de um sistema complexo e sem necessariamente entender suas causas, podendo fazer previsões para o futuro. Os big data - esses conjuntos de dados massivos que advêm de situações reais - são extremamente complexos e impossíveis de serem interpretados pela mente humana, fato que trouxe novos e poderosos métodos de análise a partir de algoritmos e uso de inteligência artificial por meio da aprendizagem de máquina (machine learning). Os dados gerados a respeito da população das grandes cidades, por exemplo, têm demandado investimento em novas tecnologias que permitam seu processamento e aproveitamento para a melhoria de serviços públicos como a erradicação de epidemias, mapeamento de ações criminosas e organização do trânsito, entre outros benefícios (ADREJEVIC; GATES, 2014).

\section{Presença das temáticas estudadas nas pesquisas da ciência da informação no Brasil}

Para identificar como a Ciência da Informação, no Brasil, vem incluindo os temas vigilância, privacidade, big data e dados pessoais em suas pesquisas, foram consultados os Anais do Encontro Nacional de Pesquisa em Ciência da Informação - ENANCIB, dos últimos 10 anos, por critério de recenticidade e pela possibilidade de serem referentes às questões envolvendo o uso das novas tecnologias de informação e comunicação - NTIC, temáticas que definem o enfoque deste estudo.

A pesquisa foi feita através de consulta a três fontes de informação: 1) o repositório Benancib, com as pesquisas apresentadas e publicadas no ENANCIB, de 1994 (sua primeira edição) até 2014; 2) Anais do XVI ENANCIB; 3) Anais do XVII ENANCIB ${ }^{1}$.

\subsection{Pesquisa no repositório Benancib}

Através de uma busca simples por cada um dos termos (assuntos), foi verificado um total de 2721 trabalhos. Deste total, 28 continham a palavra vigilância, 97 continham a palavra privacidade, 1150 continham big data e 2445 continham dados pessoais.

Observando o resultado obtido, foi definido que os dois termos com menor grau de ocorrência (vigilância e privacidade) seriam os de maior relevância para o refinamento da busca a fim de apontar os trabalhos com

${ }^{1}$ As consultas foram feitas de forma separada aos Anais do ENANCIB XVI, de 2015 e aos Anais do ENANCIB XVII, DE 2016, pois não constavam indexados no repositório Benancib, até o momento de realização desta pesquisa, contudo, os critérios utilizados foram os mesmos para possibilitar a consolidação dos dados. 
maior proximidade temática com o foco da presente pesquisa. Portanto, a partir dos 28 artigos contendo vigilância e dos 59 contendo privacidade, foi verificado o grau de importância de cada termo para cada artigo.

\subsubsection{Refinamento da busca simples por vigilância no Benancib}

A partir do resultado inicial da busca por vigilância, 17 artigos foram descartados: um por conter o termo apenas no resumo, um por conter o termo apenas no corpo do texto, 13 artigos por conterem o termo somente nas referências e, curiosamente, dois por não conterem referências sobre o assunto embora o termo estivesse presente no resumo e no corpo de texto.

Dos 11 textos restantes, três apresentavam o termo vigilância no contexto da vigilância sanitária, dois no contexto da vigilância em saúde, um no contexto de monitoramento do ambiente externo de marketing, um no contexto da observância das práticas de responsabilidade social de empresas e governos, e apenas quatro no contexto da vigilância conforme adotado neste trabalho: "a observação de informações pessoais, de forma proposital, rotineira e sistemática para fins de controle, direitos e legitimidade, gestão, influência ou proteção" (WOOD et al., 2006, p. 4, tradução nossa).

Considerando apenas os quatro textos em que o contexto de vigilância está compatível com a definição adotada na pesquisa, fez-se um quadro para a comparação dos campos em que o termo ocorre, a fim de destacar os mais pertinentes ao contexto buscado.

Quadro 1 - Seleção de textos com o termo vigilância no Benancib

Amostra: 4 trabalhos com a ocorrência do termo vigilância nas referências e em pelo menos um dos campos título, resumo, palavras-chave ou corpo do texto, compatível com o contexto ou definição de vigilância adotados na pesquisa.

\begin{tabular}{|c|c|c|c|c|c|c|c|}
\hline \multicolumn{8}{|c|}{ Método utilizado: análise de conteúdo } \\
\hline \multirow[t]{2}{*}{ Item } & \multicolumn{5}{|c|}{ Campo de ocorrência do termo vigilância } & \multirow[t]{2}{*}{ Ano } & \multirow[t]{2}{*}{ GT } \\
\hline & Título & P.Chave & Resumo & Texto & Refs. & & \\
\hline 1 & 1 & 0 & 1 & 1 & 1 & 2011 & 11 \\
\hline 2 & 1 & 1 & 1 & 1 & 1 & 2014 & 3 \\
\hline 3 & 1 & 1 & 1 & 1 & 1 & 2014 & 5 \\
\hline 4 & 0 & 0 & 0 & 1 & 1 & 2014 & 5 \\
\hline
\end{tabular}

Legenda: P.Chave: Campo de palavras-chave; Refs.: Campo de referências; 1: Ocorrência do termo no referido campo; 0: Não ocorrência do termo no referido campo.

\footnotetext{
Itens: Textos de maior pertinência contendo o termo vigilância no contexto da pesquisa

1 CAVALCANTE, Ricardo Bezerra; PINHEIRO, Marta Macedo Kerr. Sistema de informação da atenção básica: relações de poder, centralização e vigilância. In: ENCONTRO NACIONAL DE PESQUISA EM CIÊNCIA DA INFORMAÇÃO, 12., 2011, Brasília. Anais... Brasília: UnB, 2011. p. 3458-3475. 


\begin{tabular}{c|l}
\hline & $\begin{array}{l}\text { pesquisa em ciência da informação. In: ENCONTRO NACIONAL DE PESQUISA EM CIÊNCIA DA } \\
\text { INFORMAÇÃO, 15., 2014, Belo Horizonte. Anais... Belo Horizonte: UFMG, 2014. p. 1394-1407. }\end{array}$ \\
\hline 3 & $\begin{array}{l}\text { BEZERRA, Arthur Coelho; PIMENTA, Ricardo Medeiros; ORMAY, Larissa Santiago. Vigilância, vigilância } \\
\text { inversa e democracia: do panoptismo ao midiativismo. In: ENCONTRO NACIONAL DE PESQUISA EM } \\
\text { CIÊNCIA DA INFORMAÇÃO, 15., 2014, Belo Horizonte. Anais... Belo Horizonte: UFMG, 2014. p. 2528- } \\
\text { 2543. }\end{array}$ \\
\hline 4 & $\begin{array}{l}\text { ANTONIUTTI, Cleide Luciane; ALBAGLI, Sarita. Uso do big data em campanhas políticas eleitorais. In: } \\
\text { ENCONTRO NACIONAL DE PESQUISA EM CIÊNCIA DA INFORMAÇÃO, 15., 2014, Belo Horizonte. } \\
\text { Anais... Belo Horizonte: UFMG, 2014. p. 2336-2354. }\end{array}$ \\
\hline
\end{tabular}

Fonte: Dados da pesquisa.

Com este resultado, percebeu-se que o ano de 2014 foi o mais profícuo em termos de publicação de trabalhos com o tema em questão, contendo 3/4 das publicações e o GT 5 (Política, Economia e Informação) foi o que mais contribuiu, com $50 \%$ das publicações válidas, de acordo com os critérios de seleção estabelecidos neste trabalho.

\subsubsection{Refinamento da busca simples por privacidade no Benancib}

Em busca simples por privacidade, obteve-se, inicialmente, o resultado de 97 trabalhos com a ocorrência do termo. A partir deste montante inicial, foi adotado o critério de seleção em que 1) o termo privacidade deveria ocorrer no corpo do texto e em mais um campo de indexação do artigo - como título, resumo, palavras-chave ou referências; 2) a ocorrência privacidade não deveria ser apenas uma menção ou citação simples, mas ter também sua discussão ampliada no âmbito do direito, de respaldo e preservação da intimidade a partir de dados pessoais. Definido os parâmetros de seleção, foram destacados cinco trabalhos.

Quadro 2 - Seleção de trabalhos com o termo privacidade no Benancib

\begin{tabular}{l} 
Amostra: 5 trabalhos com a ocorrência do termo privacidade no corpo do texto e em mais um campo de indexação do \\
artigo e sendo discutido no âmbito do direito, de respaldo e preservação da intimidade a partir de dados pessoais. \\
\hline Método utilizado: análise de conteúdo \\
\hline \multirow{2}{*}{ Item }
\end{tabular}

Legenda: P.Chave: Campo de palavras-chave; Refs.: Campo de referências; 1: Ocorrência do termo no referido campo; 0 : Não ocorrência do termo no referido campo. 
Itens: Textos de maior pertinência contendo o termo privacidade no contexto da pesquisa

\begin{tabular}{|c|c|}
\hline 1 & $\begin{array}{l}\text { ISONI, Miguel Maurício; VIDOTTI, Silvana Aparecida Borsetti Gregorio. Percepções de segurança e ameaças } \\
\text { em ambientes de tecnologia da informação. In: ENCONTRO NACIONAL DE PESQUISA EM CIÊNCIA DA } \\
\text { INFORMAÇÃO, 8., 2007, Salvador. Anais... Salvador: UFBA, 2007. p. 1-12. }\end{array}$ \\
\hline 2 & $\begin{array}{l}\text { MARQUES, Rodrigo Moreno; PINHEIRO, Marta Macedo Kerr. Assimetria de informação na Lei Geral de } \\
\text { Telecomunicações: uma análise dialética. In: ENCONTRO NACIONAL DE PESQUISA EM CIÊNCIA DA } \\
\text { INFORMAÇÃO, 11., 2010, Rio de Janeiro. Anais... Rio de Janeiro: IBICT, 2010. p. 1-16. }\end{array}$ \\
\hline 3 & $\begin{array}{l}\text { BEZERRA, Arthur Coelho. "Culturas de vigilância", "regimes de visibilidade": novos caminhos para a } \\
\text { pesquisa em ciência da informação. In: ENCONTRO NACIONAL DE PESQUISA EM CIÊNCIA DA } \\
\text { INFORMAÇÃO, 15., 2014, Belo Horizonte. Anais... Belo Horizonte: UFMG, 2014. p. 1394-1407. }\end{array}$ \\
\hline 4 & $\begin{array}{l}\text { BEZERRA, Arthur Coelho; PIMENTA, Ricardo Medeiros; ORMAY, Larissa Santiago. Vigilância, vigilância } \\
\text { inversa e democracia: do panoptismo ao midiativismo. In: ENCONTRO NACIONAL DE PESQUISA EM } \\
\text { CIÊNCIA DA INFORMAÇÃO, 15., 2014, Belo Horizonte. Anais... Belo Horizonte: UFMG, 2014. p. 2528- } \\
2543 \text {. }\end{array}$ \\
\hline 5 & $\begin{array}{l}\text { ANTONIUTTI, Cleide Luciane; ALBAGLI, Sarita. Uso do big data em campanhas políticas eleitorais. In: } \\
\text { ENCONTRO NACIONAL DE PESQUISA EM CIÊNCIA DA INFORMAÇÃO, 15., 2014, Belo Horizonte. } \\
\text { Anais... Belo Horizonte: UFMG, 2014. p. 2336-2354. }\end{array}$ \\
\hline
\end{tabular}

Fonte: Dados da pesquisa.

Com este resultado, percebeu-se que o ano de 2014 foi o mais profícuo em termos de publicação de trabalhos com o tema em questão, contendo 3/5 das publicações e o GT 5 (Política, Economia e Informação) foi o que mais contribuiu, com $60 \%$ das publicações válidas, de acordo com os critérios de seleção estabelecidos neste trabalho.

\subsection{Pesquisa nos anais do ENANCIB XVI e XVII}

Os termos foram buscados nos Anais XVI e XVII que não se encontravam ainda indexados no repositório Benancib, no momento da pesquisa.

\subsubsection{Busca simples por vigilância}

Em buscas simples, pelo termo vigilância, feita nos Anais do ENANCIB XVI e XVII, foi obtido o seguinte resultado:

Quadro 3 - Resultado do termo vigilância nos Anais do ENANCIB XVI e XVII

\begin{tabular}{l|l|l}
\hline \multicolumn{1}{c|}{ Termo buscado } & \multicolumn{1}{c}{ Anais } & \multicolumn{1}{c}{ Itens encontrados } \\
\hline \hline \multirow{2}{*}{ Vigilância } & ENANCIB XVI & 1 \\
\cline { 2 - 3 } & ENANCIB XVII & 2 \\
\hline
\end{tabular}

Fonte: Dados da pesquisa.

Este resultado de busca foi ratificado com a aplicação dos mesmos critérios utilizados para a seleção de itens na busca feita no Benancib. 

pessoais: análise da produção da ciência da informação no Brasil

Quadro 4 - Seleção de trabalhos com o termo vigilância nos ENANCIB XVI e XVII

Amostra: 3 textos com a ocorrência do termo vigilância nas referências e em pelo menos um dos campos título, resumo, palavras-chave ou corpo do texto, compatível com o contexto ou definição de vigilância adotados na pesquisa.

\begin{tabular}{|c|c|c|c|c|c|c|c|}
\hline \multirow[t]{2}{*}{ Item } & \multicolumn{5}{|c|}{ Campo de ocorrência do termo vigilância } & \multirow[t]{2}{*}{ Ano } & \multirow[t]{2}{*}{ GT } \\
\hline & Título & P.Chave & Resumo & Texto & Refs. & & \\
\hline 1 & 1 & 1 & 1 & 1 & 0 & 2015 & 3 \\
\hline 2 & 0 & 1 & 1 & 1 & 0 & 2016 & 2 \\
\hline 3 & 1 & 1 & 1 & 1 & 1 & 2016 & 4 \\
\hline
\end{tabular}

Legenda: P.Chave: Campo de palavras-chave; Refs.: Campo de referências; 1: Ocorrência do termo no referido campo; 0 : Não ocorrência do termo no referido campo.

Itens: Textos de maior relevância contendo o termo vigilância no contexto da pesquisa

\begin{tabular}{c|l}
\hline 1 & $\begin{array}{l}\text { BEZERRA, Arthur Coelho. Vigilância e filtragem de conteúdo das redes digitais: desafios para a competência } \\
\text { crítica em informação. In: ENCONTRO NACIONAL DE PESQUISA EM CIÊNCIA DA INFORMAÇÃO, } \\
\text { 16., 2015, João Pessoa. Anais... João Pessoa: UFPB 2015. p. 1-16. }\end{array}$ \\
\hline 2 & $\begin{array}{l}\text { MOURA, Maria Aparecida. Decifra-me ou devoro-te: contexto, similaridade semântica e terminologia } \\
\text { especializadaem serviçOs de inteligência no Brasil. In: ENCONTRO NACIONAL DE PESQUISA EM } \\
\text { CIÊNCIA DA INFORMAÇÃO, 17., 2016, Salvador. Anais... Salvador: UFBA 2016. p. 1-20. }\end{array}$ \\
\hline 3 & $\begin{array}{l}\text { PÉREZ, Lisandra Guerrero Pérez; NASSIF, Mônica Erichsen. Fatores de influência na avaliação dos } \\
\text { observatórios sociais do Brasil entendidos como sistemas de vigilância informacional. In: ENCONTRO } \\
\text { NACIONAL DE PESQUISA EM CIÊNCIA DA INFORMAÇÂO, 17., 2016, Salvador. Anais... Salvador: } \\
\text { UFBA 2016. p. 1-16. }\end{array}$ \\
\hline
\end{tabular}

Fonte: Dados da pesquisa.

\subsubsection{Busca simples por privacidade nos anais do ENANCIB XVI e XVII}

Em buscas simples, pelo termo privacidade, feita nos Anais do ENANCIB XVI e XVII, foram encontrados, inicialmente, três itens. Contudo, com a aplicação dos mesmos critérios utilizados para a seleção de itens na busca feita no Benancib, dois itens foram descartados por apresentarem somente a ocorrência do termo no corpo de texto do artigo. Tendo sido realizado esse ajuste, apresenta-se abaixo o resultado obtido.

Quadro 5 - Resultado do termo privacidade nos Anais do ENANCIB XVI e XVII

\begin{tabular}{l|l|l}
\hline \multicolumn{1}{c|}{ Termo buscado } & \multicolumn{1}{|c|}{ Anais } & \multicolumn{1}{c}{ Itens encontrados } \\
\hline \hline \multirow{2}{*}{ Privacidade } & ENANCIB XVI & 1 \\
\cline { 2 - 3 } & ENANCIB XVII & 0 \\
\hline
\end{tabular}

Fonte: Dados da pesquisa.

Somente um texto foi encontrado na busca, e é apresentado no quadro seis, a seguir. 
Quadro 6 - Seleção de trabalhos com o termo privacidade nos ENANCIB XVI e XVII

\begin{tabular}{|c|c|c|c|c|c|c|c|}
\hline \multicolumn{8}{|c|}{ Método utilizado: análise de conteúdo } \\
\hline \multirow[t]{2}{*}{ Item } & \multicolumn{5}{|c|}{ Campo de ocorrência do termo privacidade } & \multirow[t]{2}{*}{ Ano } & \multirow[t]{2}{*}{ GT } \\
\hline & Título & P.Chave & Resumo & Texto & Refs. & & \\
\hline 1 & 0 & 1 & 1 & 1 & 1 & 2015 & 8 \\
\hline
\end{tabular}

Legenda: P.Chave: Campo de palavras-chave; Refs.: Campo de referências; 1: Ocorrência do termo no referido campo; 0 : Não ocorrência do termo no referido campo.

Itens: Textos de maior relevância contendo o termo privacidade no contexto da pesquisa

AFFONSO, Elaine Parra Affonso; SANT'ANA, Ricardo César Gonçalves. Anonimização de metadados de imagem digital por maio do modelo K-Anonimato. In: ENCONTRO NACIONAL DE PESQUISA EM CIÊNCIA DA INFORMAÇÃO, 16., 2015, João Pessoa. Anais... João Pessoa: UFPB 2015. p. 1-8.

Fonte: Dados da pesquisa

\section{Conclusão}

Com o propósito de identificar como os temas vigilância e privacidade, associados aos termos big data e dados pessoais, vêm sendo abordados nas pesquisas da Ciência da Informação, no Brasil, foi feita uma pesquisa nos Anais do ENANCIB dos últimos 10 anos, verificando que, apesar da abrangência do tema e do grande reflexo das questões envolvidas no cotidiano dos ambientes informatizados, a produção de artigos com este foco ainda é incipiente na pós-graduação em Ciência da Informação no Brasil.

Consolidando os resultados obtidos com a consulta das três fontes de informação, tem-se os seguintes resultados para cada termo:

No total, sete publicações abordaram o tema vigilância com o mesmo conceito utilizado neste trabalho, estando o termo em questão presente nas referências e em pelo menos um outro campo de indexação.

No ano de 2014 foram publicados três artigos (que equivalem a $42 \%$ desta amostra), seguido do ano 2016 com duas publicações, e dos anos 2011 e 2015, com uma publicação cada.

Os GTs que mais contribuíram para a abordagem deste tema foram os GTs 3 e 5, com duas publicações cada, seguidos dos GTs 2, 4 e 11, com uma publicação cada.

No total, seis publicações abordaram o tema privacidade com o mesmo conceito utilizado neste trabalho, tendo o termo em questão presente no corpo do texto e em mais um campo de indexação e sendo discutido no âmbito do direito, de respaldo e preservação da intimidade a partir de dados pessoais.

No ano de 2014 foram publicados três artigos (que equivalem a $50 \%$ desta amostra), seguido dos anos 2007, 2011 e 2015, com uma publicação cada. 
O GT que mais contribuiu para a abordagem deste tema foi o GT 5, com três publicações, seguido dos GTs 3, 4 e 8, com uma publicação cada.

Vale a pena citar que dentre os trabalhos selecionados com o termo vigilância e aqueles com o termo privacidade, três artigos são comuns aos dois grupos.

Para verificar a relação dos artigos selecionados com os termos big data e dados pessoais, foi feita uma busca simples na amostra dos grupos Vigilância (com sete itens) e Privacidade (com seis itens).

Foi verificado que, na amostra do termo vigilância, houve apenas uma ocorrência do termo big data e nenhuma ocorrência do termo dados pessoais. Enquanto que na amostra do termo privacidade, houve duas ocorrências do termo big data e uma ocorrência do termo dados pessoais.

A temática analisada na pesquisa em questão se mostra relevante, considerando as mudanças socioculturais e mercadológicas em função dos avanços tecnológicos nas últimas duas décadas, para os quais ainda não existe suporte legal que garanta a estabilidade e imparcialidade de seus efeitos. O Estado e a sociedade altamente informatizados migraram suas práticas de gestão da informação para o âmbito digital, enfatizando o poder informacional e a informação como produto. Hoje, com os modos de produção e de organização pessoal altamente dependentes dos padrões estabelecidos pela indústria da tecnologia digital, antigos conceitos sobre individualidade, propriedade e privacidade tornaram-se obsoletos e por isso precisam ser discutidos e reestabelecidos. A liberdade é posta em xeque, ao mesmo tempo em que as fronteiras que separam o público do privado tornam-se tão turvas quanto o limiar entre o real e o virtual.

Além da importância para a Ciência da Informação, da inclusão em sua agenda de pesquisas as temáticas abordadas pelo presente artigo, outros assuntos igualmente merecedores de atenção pela área foram observados durante o curso da pesquisa, mas por razões de delimitação do seu escopo e abrangência, não puderam ser aprofundados. Faz-se aqui, portanto, a menção a esses tópicos como indicação para projetos futuros, entre eles: a carência de legislação específica para a proteção e garantias da propriedade de dados pessoais; a prática da associação (assemblage) de empresas no ramo da tecnologia para a exploração do uso dos dados pessoais; e a necessária ênfase sobre a ética na captação e uso dos dados pessoais.

\section{Referências}

ADREJEVIC, M.; GATES, K. Big data surveillance: introduction. Surveillance \& Society, v. 12, n. 2, p. 185-196, 2014.

BAUMAN, Z. Modernidade líquida. Tradução Plínio Dentzien. Rio de Janeiro: Zahar, 2001.

AUMAN, Z.; LYON, D. Vigilância líquida: diálogos com David Lyon. Tradução Carlos Alberto Medeiros. Rio de Janeiro: Zahar, 2013. 
BOYD, D.; CRAWFORD, K. Critical questions for Big Data. Information, Communication \& Society, v. 15, n. 5, p. 662-679, 2012.

BRAMAN, S. Information policy and power in the information state. In: BRAMAN, S. Change of state. Massachusetts: MIT Press, 2006. p. 313328.

BRUNO, F. Máquinas de ver, modos de ser: vigilância, tecnologia e subjetividade. Porto Alegre: Sulina, 2013.

DELEUZE, G. Conversações: 1972 - 1990. Rio de Janeiro: Ed. 34, 1992.

DUMBILL, E. What is big data?: an introduction to the big data landscape. O'Reilly, 2012. Online. Disponível em: <https://beta.oreilly.com/ideas/what-is-big-data>. Acesso em: 10 jun. 2015.

FOUCAULT, M. Vigiar e punir: nascimento da prisão. 20.ed. Tradução Raquel Ramalhete. Petrópolis: Editora Vozes, 1987.

GOVERNOR, J.; NICKULL, D.; HINCHCLIFFE, D. Web 2.0 Architectures. O'Reilly Media, 2009. Dissecting Web 2.0 Examples. Online. Disponível em: <http://archive.oreilly.com/pub/a/web2/excerpts/web2architectures/chapter-3.html>. Acesso em: 10 jun. 2015.

HOOKWAY, B. Pandemonium: the rise of predatory locales in the postwar world. Princeton: Princeton Architectural Press, 2000.

MAYER-SCHONBERGER, V.; CUKIER, K. Big data: a revolution that will transform how we live, work, and think. Houghton Mifflin Harcourt: New York, 2013.

O 'REILLY, T. Big data now. Sebastopol: O'Reilly Media, 2011.

PANOPTYKON FUNDATION. Home. Panoptykon Fundation. 2015. Online. Disponível em: <en.panoptykon.org>. Acesso em: 12 jun. 2015.

WOOD, D. M. et al. A report on the surveillance society: report for the UK information commissioner's office. Surveillance Studies Network, 2 nov. 2006. <http://news.bbc.co.uk/2/shared/bsp/hi/pdfs/02_11_06_surveillance.pdf $>$. Acesso em: 23 jun. 2015. 